\title{
Conservative treatment of chondrodermatitis nodularis chronica helicis with topical nitroglycerin
}

Cabete, J.; Lencastre, A.; Paiva Lopes, M.J.; Lestre, S.; Serrão, V. Dermatology Department, Hospital de Santo António dos Capuchos - C.H.L.C., Lisbon, Portugal 


\section{Background}

- Chondrodermatitis nodularis chronica helicis $(\mathrm{CNCH})$ is a benign, painful, indurated inflammatory nodule arising on the pinna

- A disorder of transepidermal elimination of dermal connective tissue of uncertain aetiology

- Proposed therapies encompass both surgical and conservative treatment options, with varying efficacy rates

Case Presentation ... 
Patient No.

Sex

Age, $y$

No. of lesions

Location

Time of evolution

Prior treatment
M

60

1

Right antihelix

3 months
F

66

2

Left helix + antihelix

9 months

2 x CO2 Laser/PDT, 1x IL betamethasone inj.
F

86

1

Right helix

3 years

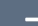

\section{Topical nitroglycerin $\mathbf{0 . 4 \%}$ ointment bid}

Concurrent treatment

Treatment duration

Response

Post topical nitroglicerin treatment

Side effects 1x IL betamethasone inj.

10 months, irregular adherence

Partial resolution of lesion and symptoms

Partial resolution of lesion and symptoms
10 months

Complete resolution of lesion and symptoms

excision 


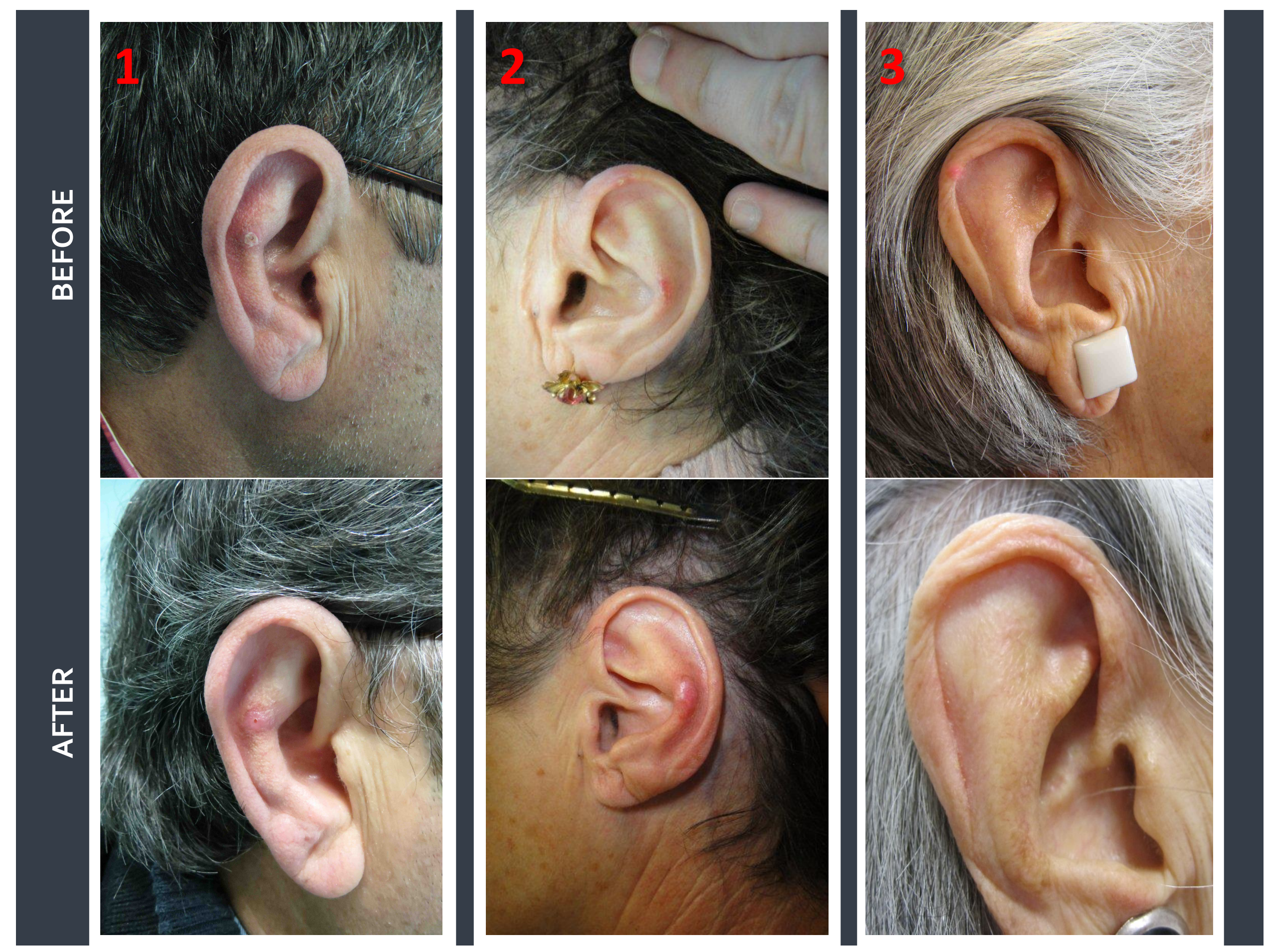




\section{Discussion}

- Dermal and chondral ischemia arising from perichondrial arterial narrowing has been recently described as a possible cause for this benign condition, hence the potential of nitroglycerin as a smooth muscle relaxant and vasodilator

- Previous case series described significant improvement in patients treated with $2 \%$ topical nitroglycerin

- $0.4 \%$ topical nitroglycerin may be as effective in pain relieve, with less side effects

- adherence may be an obstacle to treatment 


\section{Conclusions:}

- Topical nitroglycerin ointment appears to be a noninvasive alternative for the treatment of $\mathrm{CNCH}$ :

- Safe

- Easily accessible

- Non-inferior efficacy compared to other noninvasive treatments

- More studies are warranted determining the lowest effective concentration with less side effects 